\title{
Cidadania e Políticas Públicas: a Luta dos Posseiros do Figueira Branca, Pirajuí/SP, Brasil
}

\author{
João Daniel Luchini*
}

Henrique Carmona Duval**

Luiz Manoel de Moraes Camargo Almeida***

Vera Lucia Silveira Botta Ferrante****

\section{Resumo}

0 artigo analisa o crédito rural como parte de um processo histórico de lutas sociais, que permitiu a um grupo de posseiros conquistar suas terras e se constituir enquanto bairro rural de agricultores familiares. 0 referencial teórico aborda as principais questões das lutas pela terra no Brasil, os diferentes atores e identidades sociais no meio rural, com especial enfoque nos posseiros e nas políticas públicas, destacando-se o programa de crédito rural Pronaf. Questiona-se a leitura da modernização agrícola pelo prisma da padronização produtiva e salienta-se

* Cientista Social, mestre em Desenvolvimento Territorial e Meio Ambiente, UNIARA. E-mail: joaodaniel_luchini@yahoo.com.br

** Professor na Universidade Federal de São Carlos - UFSCar. Graduação em Ciências pela Universidade Estadual Paulista Júlio de Mesquita Filho (2004). Mestre em Agroecologia e Desenvolvimento Rural pela Universidade Federal de São Carlos (2009). Doutor em Ciências Sociais pela Universidade Estadual de Campinas. Pesquisador do Núcleo de Pesquisa e Documentação Rural (Uniara).E-mail: henriquecarmona@hotmail.com *** Professor no Centro de Ciências da Natureza do Campus Lagoa do Sino da Universidade Federal de São Carlos (UFSCar), na área de Desenvolvimento Territorial e Políticas Públicas. Pós-doutorado pela FEAGRI-UNICAMP na área de Políticas Públicas e Desenvolvimento Rural, Doutorado em Sociologia pela Universidade Estadual Paulista Júlio de Mesquita Filho (2006), Mestrado em Engenharia de Produção pela Universidade Federal de São Carlos (2002) e Graduação em Engenharia de Produção Agroindustrial pela Universidade Federal de São Carlos (1998).E-mail: manoel77@yahoo.com.br **** Graduação em Ciências Sociais pela Universidade Estadual Paulista Júlio de Mesquita Filho - UNESP (1966) e Doutora em Sociologia pela UNESP (1974). Livre docência na UNESP (1992), defendeu concurso de Professor Titular em 1998. Atualmente é coordenadora do Programa de Pós-Graduação em Desenvolvimento Territorial e Meio Ambiente e do PIBIC/CNPq/UNIARA da Universidade de Araraquara - UNIARA. Bolsista de Produtividade em Pesquisa do CNPq - Nível 1A. E-mail: dtmeioambiente@uniara.com.br 
a luta dos posseiros como resistência à precarização dos meios de trabalho e vida. Entrevistas com os agricultores e técnicos e aplicação de questionários semiestruturados a todos posseiros compõem a metodologia. As discussões do artigo referendam a crítica ao conceito de cidadania sob o prisma da tutela e adota a compreensão de política pública como resultante de um campo de forças sociais.

Palavras-Chave: Reconhecimento Social; Políticas Públicas; Crédito rural.

\title{
Citizenship and public policies: the struggle of squatters from Figueira Branca, Pirajuí / SP, Brazil
}

\begin{abstract}
This paper analyzes rural credit as part of a historical process of social struggles, which allowed a group of squatters to conquer their land and become a rural neighborhood of family farmers. The theoretical framework addresses the main issues of land struggles in Brazil, the different actors and social identities in rural areas with a special focus on squatters and public policies, especially the relationship with Pronaf. It is questioned the reading of the agricultural modernization through the prism of the productive standardization and the struggle of the squatters is emphasized as resistance to the precarization of the means of work and life. Interviews with farmers and technicians and application of semi-structured questionnaires compose the methodology. The article reviews the critique of the concept of citizenship under the prism of the tutelage and adopts the understanding of public policy as resulting from a field of social forces.
\end{abstract}

Keywords: Social Recognition; Public Policy; Rural Credit. 


\section{Ciudadanía y políticas públicas: la lucha de los "posseiros" del Figueira Branca, Pirajuí / SP, Brasil}

Resumen: El artículo analiza el crédito rural como parte de un proceso histórico de luchas sociales, que permitió a un grupo de "posseiros" conquistar sus tierras y constituirse como un barrio rural de agricultores familiares. El referencial teórico aborda las principales cuestiones de las luchas por la tierra en Brasil, los diferentes actores e identidades sociales en el medio rural con especial enfoque en los "posseiros" y las políticas públicas, destacándose la relación con el Pronaf. Se cuestiona la lectura de la modernización agrícola por el prisma de la estandarización productiva y se subraya la lucha de los "posseiros" como resistencia a la precarización de los medios de trabajo y vida. Entrevistas con los agricultores y técnicos y aplicación de cuestionarios semiestructurados componen la metodología. El artículo refuerza la crítica al concepto de ciudadanía bajo el prisma de la tutela y adopta la comprensión de política pública como resultante de un campo de fuerzas sociales.

Palabras clave: Reconocimiento Social; Políticas Públicas; Crédito rural.

\section{Introdução}

O presente artigo retrata a luta dos posseiros do bairro Figueira Branca pela posse do território ocupado e pelo seu reconhecimento enquanto cidadãos com direito de acesso às políticas voltadas ao desenvolvimento da agricultura familiar. A luta desses (e de outros) posseiros faz parte do mosaico dos diferentes tipos que conformam o mundo rural no Brasil e de agricultores familiares e camponeses. A luta dos posseiros do Figueira Branca surge do apoio do Movimento dos Trabalhadores Sem Terra (MST) e do assentamento União da Vitória, em Pirajuí/SP, que 
conseguem construir uma rede de apoio e solidariedade que envolveu vários atores, inclusive o poder local e parlamentares de fora da região. Esta trama contribuiu para a materialização da conquista do território e do acesso às políticas públicas.

A luta pela terra é produto da intensificação das lutas e da agitação política que envolve os movimentos de trabalhadores rurais, abrangendo diversas categorias de trabalhadores rurais como posseiros, boias-frias e trabalhadores sem-terra. Os movimentos lutam pelo direito ao uso da terra, pressionando as instituições públicas desde o século passado por políticas de reforma agrária que levem à divisão das terras e por políticas que incentivem a produção e a reprodução social dessas categorias cujo modo de vida está ligado à terra como espaço de vida e de trabalho.

A partir dos anos 90, como resultado das ações políticas desses atores, a agricultura familiar passou a ser reconhecida pelo Estado enquanto categoria econômica, através de uma definição oficial de agricultura familiar e da criação de políticas voltadas ao seu desenvolvimento (Esquerdo; Bergamasco, 2014). Reconhecimento que não pode ser interpretado como responsável pela constituição da agricultura familiar, por todo histórico do campesinato no Brasil, mas também porque a definição estatal inclui atores que também se assemelham aos agricultores patronais.

Como marco dessas políticas está o Programa Nacional de Fortalecimento da Agricultura Familiar (PRONAF) em 1995, política de crédito criada com o discurso de elevar a segurança alimentar no país, erradicar a fome e a miséria, além da modificação de paradigmas nos meios de produção, indicando o apoio às práticas produtivas sustentáveis (Rosa, 1998).

Para se tornar beneficiários do PRONAF, os agricultores familiares devem enquadrar-se e cumprir com as exigências das diretrizes do programa, sendo reconhecidos através da concessão da Declaração de Aptidão (DAP) ao PRONAF pelas instituições pú- 
blicas credenciadas. Além do PRONAF, a DAP habilita os agricultores familiares a acessarem outras políticas públicas de comercialização como o Programa de Aquisição de Alimentos (PAA) e o Programa Nacional de Alimentação Escolar (PNAE).

Assim, partindo da formação política da agricultura familiar, suas lutas para a manutenção e conquistas de novos direitos, do reconhecimento institucional como categoria econômica e da criação de políticas públicas voltadas para atender este público, este trabalho objetivou descrever a formação social dos posseiros do Figueira Branca de Pirajuí/SP. Foram investigadas 10 famílias que compõem o grupo, suas trajetórias política e social, lutas pela terra, a trama de atores envolvidos e que colaboraram com o processo do seu reconhecimento social, materializado na obtenção da DAP, que os reconheceu enquanto sujeitos de direito com poder de acessar as políticas voltadas ao desenvolvimento da agricultura familiar. Objetivou-se demonstrar os processos pelos quais os posseiros acessaram as políticas públicas, suas expectativas e dificuldades para obter a DAP e o crédito do PRONAF, os meios de produção, se financiados ou não, o acesso às políticas de comercialização e os impactos sobre a reprodução social das famílias.

É interessante frisar que a trajetória deste trabalho aponta para mudanças significativas em relação à perspectiva do objeto inicial de estudo, principalmente após as idas a campo para as entrevistas com os agricultores familiares, que supostamente eram assentados ${ }^{1}$.

Isso porque o objetivo inicial da pesquisa era descrever as diferentes estratégias utilizadas pelos assentados do Figueira Branteve com membros da Associação dos Produtores Rurais do Assentamento Vitória (ASPRAVI), formado por agricultores que se autodenominavam sem-terra e participavam de movimento de trabalhadores sem-terra, caso do MST e da CPT. 
ca e Vitória do município de Pirajuí/SP para obter e utilizar o crédito do PRONAF, de forma a fazer analiticamente uma comparação entre os dois grupos.

Com base nos relatos de campo e nos dados coletados houve o reconhecimento do Figueira Branca formado por um grupo de posseiros, o que exigiu uma reorientação do estudo, em vista de serem grupos com histórico e natureza jurídica distintos, o que vai afetar o acesso ao crédito do PRONAF. A revelação de que o grupo não era de assentados, mas de posseiros, foi importante para a (re)definição dos rumos da pesquisa em termos de categoria social analisada. Principalmente, pelos dados coletados constatarem um grupo em meio ao processo de regularização fundiária da área ocupada, pelo fato dos posseiros terem conquistado obras de infraestrutura no local como energia elétrica, terem providenciado a divisão dos lotes, construção de moradias e terem acessado políticas públicas como o PRONAF.

O grupo de posseiros do Figueira não estava sob a custódia do INCRA ou ITESP, ou seja, suas ações eram dotadas de maior autonomia do que os assentados, em relação ao Estado, inclusive utilizando recursos próprios para a construção de moradias, infraestrutura e meios de produção. Tratou-se, pois, de investigar o processo de construção social de uma categoria-posseiros e de sua luta pelos direitos dos agricultores familiares e pela construção de um modo de vida.

\section{M etodologia}

Os sujeitos da pesquisa são dez famílias de posseiros do Figueira Branca. De início, foi efetuado um levantamento do histórico da área do Figueira Branca, utilizando-se relatos das entrevistas com os agricultores da área, líderes, análise de fotografias, atas de reuniões, jornais da época, consulta a sites na internet, ou seja, explorar a memória do local juntamente com seus ocupantes. 
Foi elaborado um questionário semiestruturado para os posseiros, estendido para todas as famílias, com variáveis quantitativas que foram anotadas e colocadas em planilha, além da gravação, com consenso do entrevistado, para posterior apreciação.

Além das famílias, foram entrevistados os técnicos da Casa da Agricultura local, responsáveis pela emissão da DAP e pela assistência técnica, funcionários ligados à contratação do crédito rural do PRONAF nas agências da instituição financeira com a atribuição de liberação do crédito.

Posteriormente, também foi utilizado um roteiro de entrevistas com perguntas sobre os meios de produção dos posseiros, alteração após o reconhecimento do grupo pela declaração de posse e possibilidade que o documento trouxe de acessarem $o$ PRONAF, bem como outras políticas públicas, como o PAA e o PNAE. As diversas entrevistas permitiram obter detalhes e diferentes versões do histórico de obtenção da DAP, possibilitando confrontar as versões dos posseiros e a dos técnicos da Coordenadoria de Assistência Técnica Integral (CATI), responsáveis pelo cadastramento.

Outras etapas da metodologia foram as consultas a dados secundários do Censo Agropecuário do Instituto Brasileiro de Geografia e Estatísticas (IBGE), Anuário Estatístico do Crédito Rural do Banco Central do Brasil (BCB), dados acerca de valores liberados pelo programa através dos sites do Ministério do Desenvolvimento Agrário (MDA), Instituto de Terras do Estado de São Paulo (ITESP) e Instituto Nacional de Colonização e Reforma Agrária (INCRA). Paralelamente ao trabalho de campo, revisões bibliográficas foram fundamentais na metodologia. 


\section{Revendo Referenciais T eóricos}

Agricultura familiar: identidade política e disputas por terras

A discussão em torno da agricultura familiar é ampla e com diversos aspectos que apontam para dimensões peculiares ao longo do seu processo de formação e desenvolvimento. Neste artigo serão apresentadas características que possam firmar um conceito de agricultura familiar, centrado na exposição das condicionantes em torno da disputa por terra, direitos, nas rupturas e continuidades apresentadas e em sua reprodução social, perpassando, portanto, a noção que advém das políticas públicas.

A agricultura familiar, além de envolver uma gama de diferentes atores sociais no território brasileiro, não pode ser considerada imutável, como uma categoria possuidora de única essência, hermética, mas trata-se de uma categoria histórica, que se transforma. Apesar desta diversidade, sua identificação tem como elemento comum a família que é ao mesmo tempo a proprietária dos meios de produção, gerencia e trabalha no estabelecimento (Wanderley, 1996; 2003). Para Lamarche (1993), a heterogeneidade explica a resistência e a presença da agricultura familiar, principalmente nas unidades de produção e na relação com o mercado. 0 autor expõe dois modelos para definir conceitualmente a agricultura familiar, sendo o tipo original próximo ao camponês, com trabalho familiar organizado e centrado nas necessidades de consumo da família, já o tipo ideal atrela sua unidade produtiva às do mercado, podendo utilizar mão de obra de terceiros.

Segundo Godoi, Menezes e Marin (2009), não é possível realizar um estudo sobre a agricultura familiar sem que se faça recortes bem precisos sobre a identidade social de cada tipo de comunidade, ou seja, sobre quais os princípios de diferenciação no espaço social. Dentro desse grande conceito, a agricultura familiar, existe sempre uma infinidade de singularidades. Para Neves 
(2013), são diferentes as lutas de povos tradicionais, tais como os quilombolas, ou de atingidos por grandes empreendimentos, daquelas dos assentados da reforma agrária, ou seja, acabam sendo entes jurídicos diferentes e que lutam por direitos específicos, embora existam pontos em comum em suas pautas e em suas histórias - tais como transformações socioespaciais, subordinação às relações de propriedade da terra, aspectos do modo de vida, dentre outros. Diferentes igualmente dos posseiros do Figueira Branca, analisados neste artigo.

Por outro lado, podemos constatar o fato ao observar que, na "condição camponesa" ou na "agricultura familiar", existem famílias nas mais variadas situações em relação ao mercado: desde aquelas que possuem contratos de arrendamento capitalista com a agricultura patronal e que, com isto, não possuem um projeto de trabalho familiar e os membros da família trabalham fora da propriedade, até os que diversificam ao extremo suas propriedades, nas quais participam do processo de trabalho homens, mulheres, jovens e idosos, que comercializam em feiras e em programas institucionais. Há também as que estão no meio termo, que fazem tanto uma como outra coisa. Para compreendê-las como identidades sociais e políticas em movimento, é necessário reconhecer-lhes as singularidades, aquilo que as diferencia e não somente aquilo que as dilui em categorias abrangentes e genéricas.

Antes de debatermos o processo de modernização da agricultura familiar e sua essência camponesa, torna-se importante frisar a participação dos agricultores familiares no ato de sua construção social, da identidade política, nas lutas e disputas por terras, na modernização, no reconhecimento social e nas políticas públicas. A trajetória histórica desta categoria social envolveu disputas marcadas por contradições, exclusões e resiliências expressas em produtivas e modos de vida durante a modernização da agricultura brasileira intensificada durante a década de 1960. 
Com o impulso à modernização, em 1965 foi criado o Sistema Nacional de Crédito Rural (SNCR), crédito subvencionado que visava o investimento e custeio das atividades agropecuárias, tais como aquisição de máquinas, implementos e produtos químicos, orientado, principalmente, para suprir as demandas dos grandes agricultores.

Outro importante fato ocorrido na década de 1960 foi a Lei 4.504 de 30 de novembro de 1964, o Estatuto da Terra, constituído durante a ditadura militar e que tratava de questões como a reforma agrária. No texto do estatuto estavam delimitados os conceitos de novas categorias e tipos de propriedades existentes no meio rural, como o minifúndio e o latifúndio, levando em conta a extensão, a exploração e a empresa rural, de maneira que seriam desapropriadas as terras que não cumprissem sua função social, produzindo para a família e para a sociedade, com respeito ao meio ambiente e ao cumprimento da legislação trabalhista.

Para Martins (1999) o Estatuto da Terra procurou classificar usos e extensões de propriedade, de modo a formular um conceito operacional de latifúndio que incluía terrenos não extensos, mas explorados, incluía minifúndios e conceituava as empresas rurais de modo positivo, ou seja, afastava as possibilidades de serem inclusas nas desapropriações. Portanto, a lei da reforma agrária impulsionou a exploração de grandes conglomerados empresariais, impulsionando a expansão das fronteiras agrícolas, auxiliando a consolidação de um modelo de agricultura altamente mecanizado e capitalista.

Diante desse quadro, elevou-se o número das lutas dos trabalhadores rurais, apesar da censura e repressão ampliada pela militarização das questões fundiárias. A utilização de jagunços, por grandes proprietários para expulsarem os posseiros de suas terras, contava com a conivência da polícia e da justiça, ocorrendo num espaço de legalidade e diminuindo as chances dos camponeses. Por se tratar de uma luta não institucionalizada, o con- 
flito dos posseiros possui curta duração culminando com vitória dos camponeses ou dos proprietários ou grileiros. Quando os últimos vencem, os primeiros tomam a decisão de se tornarem posseiros em outras áreas ou se proletarizarem (Martins, 1984).

Com a abertura política da década de 1980, organizações tais como Movimento dos Trabalhadores Sem Terra (MST), Movimento dos Pequenos Agricultores (MPA), Movimento dos Atingidos por Barragens (MAB), movimento sindical dos trabalhadores rurais aglutinados na Confederação Nacional dos Trabalhadores na Agricultura (CONTAG), partidos políticos como o PCB, o PCdoB e o PT juntaram-se, passando a dirigir os movimentos dos trabalhadores rurais pressionando por políticas de reforma agrária.

As trajetórias políticas dos trabalhadores rurais aliadas à abertura política da década de 1980 fizeram com que ganhassem maior notoriedade política e visibilidade social na construção de seus direitos. Suas lutas políticas ocasionaram um maior reconhecimento social para que pudessem construir sua identidade, exercer sua cidadania ${ }^{2}$, através do processo de reforma agrária e consequente divisão de terras.

Reconhecimento social é entendido no sentido ético, como construção objetiva, ou seja, para ocorrer são necessários valores que permitam reconhecer no grupo ações que o dignifiquem eticamente, sem se deixar levar por posicionamentos subjetivos (Souza, 2000).

Em uma posição, até certo ponto, diferenciada, na teoria social de Honneth (2003), é possível se discutir a ampliação das relações intersubjetivas do reconhecimento social integrada a um 
processo de individuação que resulta de lutas sociais por meio das quais podem ser realizadas transformações de ordem normativa. Tais processos de luta são inseparáveis de um conjunto de direitos relacionados à expansão crescente de sua autonomia. As lutas por reconhecimento constituem-se, pois, em contextos históricos e culturais particulares, mas postulam um reconhecimento social e normativo de seus respectivos modos de vida.

As lutas por reconhecimento e a defesa da identidade e da autonomia podem assumir a forma da luta pela igualdade de acesso ao direito de justiça e ao uso equitativo dos recursos públicos, no caso analisado, relacionados às políticas de crédito.

Essa luta pelo reconhecimento por direitos reflete a busca da população do campo por ser identificada como cidadã. Para Santos (2014), ser reconhecido como cidadão é se fazer valer do lugar que possui na sociedade, lutando para mudar ou permanecer nele, legitimar sua função social na posição e no papel que cumprem.

Nesse processo, assume-se a conceituação de identidade de Sousa Santos (1995), entendida como uma síntese de identificações em curso, com resultados marcados pela transitoriedade. Diante desse referencial, assumido no artigo, a identidade não pode ser compreendida jamais de forma estática, como algo pronto e definitivo, visto que é uma construção incessante de si em movimentos contraditórios.

\section{M odernização, Reconhecimento Social e Lutas por D ireitos}

O diálogo institucionalizado segue para a constituição de políticas públicas, entretanto ao Estado cabia reconhecer, de forma objetiva, o seu entendimento por agricultura familiar, nas suas diferentes facetas e nas disputas que vivenciavam, tanto em torno das terras quanto do mercado. 
O trabalho da FAO/INCRA de 1994 coordenado por Carlos Guanzirolli tinha como objetivo central elaborar diretrizes para um novo desenvolvimento rural para o Brasil. Como resultado principal tivemos a elaboração de um modelo classificatório da agricultura que a dividia em dois grupos, "patronal" e "familiar", sendo o primeiro marcado pela separação entre gestão e trabalho, ênfase na especialização produtiva, práticas padronizadas e uso de trabalho assalariado. Já o familiar, com uma íntima relação entre trabalho e gestão, direção produtiva pelo proprietário, diversificação produtiva, podendo usar trabalho assalariado eventualmente (Picolotto, 2015).

Tivemos a criação do decreto 1.946, de 28 de junho de 1996, que dispõe sobre a criação do PRONAF (Programa Nacional de Fortalecimento da Agricultura Familiar), para proporcionar o financiamento de tecnologias, pesquisas e difusão de técnicas que pudessem elevar o nível de produtividade conjugado à proteção ao meio ambiente.

A Resolução do BACEN 2191 de 24 de agosto de 1996 regulamenta o crédito do PRONAF, definindo os critérios para a aptidão dos agricultores ao programa através da DAP:

- Explore a terra na condição de proprietário, posseiro, arrendatário ou posseiro;

- Não mantenha empregado permanente, podendo sazonalmente quando a atividade agrícola permitir;

- Não detenha área maior do que quatro Módulos Fiscais3;

3 Módulo fiscal é uma unidade de medida expressa em ha. Seu tamanho varia para cada município e depende principalmente das condições de produção: dinâmica de mercado, infraestrutura instalada, disponibilidade tecnológica, além de aspectos naturais como água e solo. Quanto mais disponíveis essas condições, menor o tamanho da área necessária para a obtenção de rentabilidade ali desenvolvida. 0 tamanho máximo para um módulo é de 110 ha e o menor é fixado em 5ha. (INCRA, 2017). 
- Detenha, no mínimo, 80\% da renda bruta anual proveniente de exploração agropecuária ou extrativa;

- Resida na propriedade ou em aglomerado urbano próximo à área explorada (Bianchini, 2015);

Nesse momento, a agricultura familiar passa a ser reconhecida como uma categoria econômica ganhando destaque nas questões relacionadas ao desenvolvimento rural. 0 reconhecimento institucional teve no PRONAF um importante elemento de valorização, constituindo-se como política pública para reverter as desigualdades entre a agricultura patronal e a familiar (Silva et al., 2015). Entretanto, a visão de que a agricultura familiar foi criada ou constituída pelo Estado através do PRONAF deve ser criticada, acertadamente.

O conceito de agricultura familiar passa por questionamentos por limitar o contingente de atores à produção e por área explorada, excluindo, principalmente, os produtores mais vulneráveis. A pressão dos movimentos sociais sugere mudanças conceituais, como a Lei da Agricultura Familiar 11.326, de 24 de julho de 2006, a qual estabelece novas diretrizes para a agricultura familiar brasileira, incluindo como agricultores familiares silvicultores, aquicultores, extrativistas, pescadores, povos indígenas e quilombolas, um universo que envolve modos de vida diversos.

Os programas de incentivo à agricultura familiar, como o crédito do PRONAF, tendem a privilegiar agricultores que seguem tendências da lógica de mercado derivada da "Revolução Verde", centrada no aumento da capacidade produtiva através da especialização produtiva, mecanização e uso de insumos químicos. Essa dicotomia produtiva aponta para um cenário ideal, de concorrência sadia e acesso para todos os agricultores, sem distinção. Porém, a diversidade da agricultura familiar sinaliza para um cenário que muitos agricultores não conseguem assimilar e 
acessar, culminando novamente na marginalização deste contingente populacional (Carneiro, 1997). A idealização transformou-se em precarização das relações sociais, principalmente na intensificação do assalariamento rural.

A configuração das famílias quanto à produção ficou parametrizada nos diferentes modelos das DAP, conforme quadro a seguir, levando em conta que a Unidade Familiar de Produção Rural (UFPR) mantém índices produtivos que carecem de um modelo que irá direcioná-la a linhas de crédito.

Quadro 1 - Modelos e características da DAP

\begin{tabular}{|c|l|}
\hline MODELO DA DAP & CARACTERÍSTICAS DO PÚBLICO-ALVO \\
\hline 1.9 .1 & $\begin{array}{l}\text { UFPR beneficiárias do Programa Nacional da Reforma Agrária e } \\
\text { do Crédito Fundiário. }\end{array}$ \\
\hline 1.9 .2 & UFPR com renda bruta anual de até $\mathrm{R} \$ 20.000,00$. \\
\hline 1.9 .3 & $\begin{array}{l}\text { UFPR com renda bruta anual superior a R } \$ 20.000,00 \text { até } \mathrm{R} \$ \\
360.000,00 .\end{array}$ \\
\hline 2.0 & Filho(a)s das UFPR detentores da DAP de qualquer modelo. \\
\hline 2.1 & $\begin{array}{l}\text { Mulheres agregadas na UFPR com DAP emitida de qualquer } \\
\text { modelo. }\end{array}$ \\
\hline 3.2 & $\begin{array}{l}\text { Pessoa Jurídica (PJ) composta por agricultores familiares deten- } \\
\text { tores da DAP de quaisquer modelos. }\end{array}$ \\
\hline 3.3 & $\begin{array}{l}\text { Cooperativas Centrais compostas por Cooperativas Singulares de } \\
\text { Agricultores Familiares. }\end{array}$ \\
\hline
\end{tabular}

Fonte: Elaborado a partir dos dados disponíveis em: www.mda.gov.br.

A divisão por grupos define a estratificação criada pelo Estado no interior da agricultura familiar para a execução da política pública, sendo os critérios adotados para a definição de cunho determinista e linear. 0 ideal da estratificação é a migração entre os grupos pelos agricultores que tomam crédito, seguindo uma direção de acumulação a partir do ideal de utilização de recursos tecnológicos em consonância com o agronegócio (Silva et al., 2015). 
O PRONAF, no âmbito institucional, poderia ser encarado como uma política de compensação para tratar de anomalias históricas na construção social e reparar os privilégios de uma parcela de agricultores num modelo de desenvolvimento que deixou a agricultura familiar às margens do processo. Além da inserção social, o PRONAF supostamente teria por objetivo a indução para a produção de alimentos, entretanto, as práticas da sua política corroboradas pelos dados acima apontam para uma tendência em incentivar a produção de commodities, minimizando suas diretrizes (Henig; Santos, 2016).

Para os autores acima, apesar dessa diligência, o PRONAF pode ser considerado como uma válvula motriz na conquista da cidadania pelos agricultores familiares, pelo reconhecimento da categoria, por proporcionar equiparação dos meios de produção em relação ao agronegócio, promovendo oportunidades de inclusão e assegurando direitos. Porém, como crítica a esse argumento está o direcionamento dos investimentos para agricultores capitalizados, inseridos na lógica produtivista de acumulação, associados ou cooperados, suscetíveis ao consumo de insumos e máquinas agrícolas, especializados em produtos voltados ao mercado externo, como soja e milho, prevendo que estes pudessem honrar com seus compromissos, reembolsando os investimentos públicos (Carneiro, 1997). Na prática, uma política pública com toda a aparência de favorecer a pequena agricultura familiar, mas cujos fundos estão concentrados nas parcelas dessa categoria social mais capitalizada, tecnificada com base em pacotes da revolução verde, para uma produção ligada ao agronegócio e a mercados de cadeias longas.

Para Aquino (2009), a escolha por esse perfil de agricultores passa pelo crivo dos bancos financiadores, já que estes são mais propensos a cumprir com as exigências de garantia e contrapartida bancária. 
Conforme Grisa e Schneider (2015), o PRONAF sintetizou uma primeira geração de políticas públicas orientadas para a agricultura familiar, reconhecendo estes atores como parcela importante no plano de desenvolvimento do país, privilegiando ações voltadas à produção e à questão agrária. Cabe lembrar que esse período fora marcado pelos intensos embates entre os movimentos sociais e forças contrárias à implementação das políticas públicas, culminando com ações do Estado visando medidas paliativas para cessar os conflitos por terra. Não pode, portanto, ser considerado como expressão de uma cidadania tutelada, mas de um processo de conquistas por lutas e embates.

Os referidos autores aludem para uma segunda geração de políticas públicas que tendeu para ações assistencialistas na intenção do Estado agir sobre as "falhas do mercado", notadamente no período da intensificação das políticas neoliberais adotadas pelos governos na metade da década de 1990. Referem-se à terceira geração de políticas públicas, que tratava da comercialização da produção dos alimentos da agricultura familiar. Com o programa "Fome Zero", os mercados institucionais tiveram papel preponderante na formulação do PAA em 2003, principalmente na alimentação escolar.

As políticas públicas, entendidas enquanto processos, podem ser caracterizadas como atributo de provimento do Estado, como um reconhecimento social de que os agricultores familiares são produtores de alimentos, sendo, portanto, potenciais cidadãos beneficiários de direitos e deveres para com a sociedade. Todavia, seus direitos são frequentemente fragilizados pelas relações políticas e econômicas entre indivíduo-Estado, indivíduo-sociedade e sociedade-Estado (Wagner; Gehlen; Schultz, 2016). 


\section{Resultados: Espaço e T rama dos Sujeitos Sociais das Lutas ao Reconhecimento Social}

O bairro Figueira Branca está localizado à margem da vicinal Anibal Haman, no município de Pirajuí/SP, trecho conhecido como "estrada da penitenciária" justamente por ligar a área urbana do município à penitenciária estadual Luiz Gonzaga Vieira. Essa estrada é mantida pelo Departamento de Estradas e Rodagem do Estado de São Paulo (DER-SP), juntamente com as cercas que limitam o acesso do Figueira Branca. Nas visitas realizadas ao local, essas infraestruturas estavam bem mantidas, mesmo em épocas de chuva, provavelmente pelo fato deste ser o único acesso viário asfaltado de ligação com a penitenciária.

No início da ocupação, o coordenador do núcleo urbano do MST foi à prefeitura e ao cartório de registro de imóveis para obter mais informações sobre a área e descobriu-se que a mesma era considerada improdutiva, dada a não emissão de notas fiscais de venda de produção nos últimos vinte anos, além de estar com Imposto Territorial Urbano (ITR) e Certificado do Cadastro Rural (CCIR) em atraso.

Diante das informações, o grupo planejou a ocupação com dez famílias selecionadas pelo MST nos municípios da região (Presidente Alves, Balbinos, Guarantã). As reuniões do núcleo urbano do MST ocorriam na sede do assentamento Vitória, que faz divisa com a área do Figueira Branca, num prédio que pertencia à extinta Companhia de Agricultura, Imigração e Colonização (CAIC) e que foi incorporada pelos assentados.

Para Martins (2003), o MST age no sentido de homogeneizar o grupo, minimizando os efeitos das diferenças ideológicas e políticas, na tentativa de criar ações e valores coletivos. Com relação ao processo de ocupação de terras e da ação do grupo, por mais que o discurso esteja afinado com a questão da justiça social que suas ações poderão oferecer, o ato de ocupação gera resistência 
em alguns indivíduos por entenderem que a ação é ilegal, por mais que a legitimem como moral.

Os posseiros ficaram conhecidos na vizinhança como "moradores do lixão", pela proximidade dos lotes com o aterro sanitário do município e como forma de difamar a sua imagem e do movimento. Como parte da identidade do grupo, o nome não agradava e, em uma das reuniões, os agricultores decidiram atribuir um nome que demonstrasse alguma característica que pudesse ser marcante.

Os relatos colhidos contam que o nome veio em homenagem à vistosa árvore localizada na estrada que liga os lotes e que os abrigava do sol nos dias das reuniões, a Figueira Branca. A construção da identidade demonstra a ação do grupo para visualização de um ícone simbólico que reunisse aspectos que denotem particularidades em comum e, assim, atribuir características que reafirmem a sua singularidade enquanto grupo social.

Ficar conhecido como moradores de uma área de lixão não é bem quisto e, portanto, a solicitação da alteração do nome de modo conjunto, decidido em assembleia, ressalta a importância de formação da identidade grupal, sua construção e implantação. Com orgulho, um agricultor afirmou que suas correspondências já vêm como "bairro da Figueira Branca", uma conquista com repercussões materiais e simbólicas para esta população rural.

Para Chagas (2014) a identidade do grupo ocorre por intermédio de fatores como o histórico de lutas e permanência na terra, a origem rural das famílias, a relação com o poder local e o reconhecimento social podendo se materializar em símbolos que irão permear a trajetória do grupo social, no nosso caso, a árvore.

A formação territorial do Figueira Branca, de acordo com Santos (2014), mostra que cidadania é uma coisa que se aprende, e o tornar-se cidadão torna as pessoas portadoras de prerrogati- 
vas sociais em luta para romper a histórica negação de direitos, como casa, luz, água, trabalho, saúde, educação e políticas públicas de apoio produtivo. Assim, para os posseiros, a luta pela terra é a base para a conquista de maior equidade e cidadania.

Segundo os relatos, os agricultores possuíam experiências na terra e logo começaram a produzir nos lotes. As primeiras produções eram para consumo da família e trato do gado leiteiro, comercializando o excedente nos mercados locais e o leite para laticínios da região através de contratos de parceria firmados entre os laticínios e agricultores da região, por intermédio da Associação dos Agricultores do Assentamento Vitória (ASPRAVI) ${ }^{4}$. Cabe destacar que os posseiros do Figueira juntaram-se aos agricultores familiares do assentamento de área vizinha, assentamento Vitória, para constituição e sedimentação dessa associação de produtores rurais para que houvesse, juntamente com outros agricultores familiares da região, maior poder de barganha na concessão de contratos com os laticínios. A ASPRAVI foi formada em 2011, inicialmente com os assentados do Vitória e os posseiros do Figueira Branca, para posteriormente absorver agricultores familiares da região.

As vendas de leite para os laticínios exigiam a emissão de nota fiscal servindo como mais um forte argumento em favor da regularização da situação fundiária da área. Com auxílio do MST, da CPT, da Câmara Municipal e da Prefeitura Municipal foi emitida a declaração de posse mansa e pacífica com timbre da prefeitura indicando que no movimento de ocupação da área não existia nenhuma contestação que pudesse se opor ao processo de ocupação.

Esse documento abre portas para o processo de legalização da área, visto que cada lote recebeu uma via com o nome da área, tamanho e delimitação, além de indicar o início da ocupação, 
dando publicidade ao ato para futuros requerimentos na justiça por usucapião.

\section{D imensões do modo de vida: produção e reprodução social}

Passados dois anos de permanência na área, três posseiros construíram suas casas com recursos próprios e em sistema de mutirão. Houve contratação de pedreiro, mas o trabalho coletivo dominou grande parte das ações, já que houve muito trabalho para buscar água no córrego e no poço coletivo para uso na construção, além de fazer a mistura do concreto manualmente, dada a ausência de betoneiras por falta de energia elétrica.

As construções das casas juntamente com a declaração de posse foram importantes para a solicitação da energia elétrica aos lotes por intermédio do "Programa Luz para Todos". As casas de alvenaria simbolizaram o início da ocupação de área e legitimaram, junto aos agricultores familiares vizinhos, o ideal de que havia no local trabalhadores interessados em trabalhar e viver na terra, o que consolidou, ainda mais, a conquista daquele território.

Os posseiros entrevistados afirmaram que esse fato serviu para sedimentar o grupo, diante da desconfiança de alguns agricultores de construírem casas correndo o risco de serem expulsos da terra e perderem o investimento. Juntamente com a energia elétrica veio a perfuração dos poços artesianos e a instalação de uma bomba elétrica para a extração da água para irrigar as lavouras e abastecer as casas, contribuindo para o escoamento do esgoto para as fossas sépticas.

Cabe destacar que os recursos financeiros utilizados para a construção dessas benfeitorias foram dos próprios posseiros que não contaram, nesta fase, com qualquer tipo de financiamento para investimento, dada a sua condição de posseiros e não serem assistidos nem pelo INCRA, nem pelo ITESP. 
Também, a aquisição dos meios de produção foi realizada com recursos próprios, sem o benefício das políticas públicas de crédito do PRONAF e de moradia (Minha Casa Minha Vida Rural) que pudessem lhes auxiliar na construção de moradias ou mesmo aquisição de maquinários agrícolas.

Posteriormente, a obtenção da DAP por alguns posseiros permitiu o financiamento dos meios de produção. Além da participação nas políticas públicas de comercialização, isto consolidou o reconhecimento desses posseiros enquanto agricultores familiares diante das instituições públicas (local, estadual e federal).

O quadro a seguir apresenta uma síntese dos meios de produção dos posseiros, diferenciando as fontes de recursos utilizadas na aquisição, dividindo-os em financiados ou adquiridos com recursos próprios.

Quadro 2 - Meios de Produção e fontes de financiamento

\begin{tabular}{|c|c|c|c|c|c|c|c|c|c|c|}
\hline $\begin{array}{l}\text { Bens de } \\
\text { Produção }\end{array}$ & 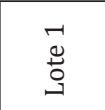 & 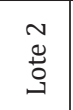 & $\begin{array}{l}m \\
0 \\
0 \\
0\end{array}$ & $\begin{array}{l}+ \\
\stackrel{0}{0} \\
0 \\
\end{array}$ & $\begin{array}{l}10 \\
0 \\
0 \\
0\end{array}$ & $\begin{array}{l}0 \\
0 \\
0 \\
0\end{array}$ & 包 & $\begin{array}{l}\infty \\
0 \\
0 \\
0 \\
\end{array}$ & $\begin{array}{l}0 \\
0 \\
0 \\
0\end{array}$ & $\begin{array}{l}\circ \\
\stackrel{0}{0} \\
\stackrel{0}{0} \\
0\end{array}$ \\
\hline Camionete & & & & & $1(\mathrm{P})$ & & & & & \\
\hline Caminhão & $1(\mathrm{P})$ & & & & & & & & & \\
\hline Chorumeiro & & & & & $1(\mathrm{P})$ & & & & & \\
\hline Curral & $1(\mathrm{P})$ & $1(\mathrm{P})$ & & $1(\mathrm{P})$ & $1(\mathrm{P})$ & & $1(\mathrm{P})$ & & & $1(\mathrm{P})$ \\
\hline Estufa & $1(\mathrm{~F})$ & $3(\mathrm{~F})$ & $\begin{array}{c}2 \\
(1 \mathrm{P} / 1 \mathrm{~F})\end{array}$ & & $1(\mathrm{~F})$ & $3(\mathrm{~F})$ & $\begin{array}{c}2 \\
(1 \mathrm{P} / 1 \mathrm{~F})\end{array}$ & $2(\mathrm{P})$ & & $2(F)$ \\
\hline Mangueiro & & & & & $1(\mathrm{P})$ & & & & & \\
\hline $\begin{array}{l}\text { Matriz } \\
\text { Bovina } \\
\text { Leiteira }\end{array}$ & $\begin{array}{c}15 \\
(9 \mathrm{P} / 6 \mathrm{~F})\end{array}$ & & & & $\begin{array}{c}15 \\
(5 \mathrm{P} / 10 \mathrm{~F})\end{array}$ & & $\begin{array}{c}12 \\
(4 \mathrm{P} / 8 \mathrm{~F})\end{array}$ & & & $10(\mathrm{P})$ \\
\hline Novilha & & & & $6(\mathrm{P})$ & & & & & & \\
\hline Trator & & & & & $1(\mathrm{P})$ & & $1(\mathrm{P})$ & & & \\
\hline Tulha & $1(\mathrm{P})$ & & & & & & & & & \\
\hline
\end{tabular}

Legendas: P (adquiridas com recursos próprios); F (adquiridos por intermédio de financiamentos)

Fonte: Elaborado pelos autores. 
Os financiamentos citados pelos posseiros, que se restringem a apenas estufas e gado leiteiro, foram efetuados através dos recursos do PRONAF, modalidades Mais Alimentos e Custeio, pelo Banco do Brasil, instituição financeira responsável pela administração do crédito no município de Pirajuí. Diferentemente dos assentados, que possuem linhas de crédito com condições mais favoráveis e propícias para iniciantes, como o PRONAF A, os posseiros, inicialmente, tiveram que arcar com os custos de produção e de aquisição dos meios de produção, mantendo uma agenda produtiva que durou mais de um ano para poder comprovar uma produtividade compatível com as exigências da DAP e, a partir desta documentação, acessar as linhas de crédito supracitadas.

Os posseiros que financiaram seus bens de produção revelaram as dificuldades que encontraram para acessar e utilizar o crédito do PRONAF. A primeira dificuldade consistiu na obtenção da DAP, uma vez que não estavam vinculados ao INCRA, nem ao ITESP e, por não terem acesso à assistência técnica dos assentados, tiveram que recorrer à Casa da Agricultura local, mas com muita resistência do técnico local e do regional. Foi necessário envio de um abaixo assinado de todos os integrantes à CATI Campinas, buscar o apoio de deputados estaduais e de representantes do MST para que a CATI reconhecesse a declaração de posse e emitisse as DAP's.

Entretanto, como demonstra Wagner, Gelhen e Schultz (2016), por mais que o grupo pudesse deter o direito reconhecido com base nas prerrogativas legais, foi necessário um conjunto de pressões oriundo de diferentes atores sociais e políticos para a materialização do direito. A legalidade não garante, por si só, a cidadania, já que a burocracia não atende, da mesma maneira, os diferentes sujeitos que compõem o universo da agricultura familiar. 
A burocracia bancária, a exigência de garantia, questões cadastrais e a demora na liberação do crédito foram os principais empecilhos apontados pelos posseiros para a contratação do crédito rural do PRONAF. A exigência de "muito papel" inibe os anseios de buscar o financiamento, como revelou o agricultor 1 , que planeja construir mais uma estufa, porém não gosta de ir ao banco para levar a "papelada". Além disso, o prazo informado pelo banco não coincide com o seu planejamento da produção.

A seguir, o Gráfico 1 demonstra a produção comercializável dos lotes, dividida entre a produção pecuária e a agrícola.

Gráfico 1 - Produção comercializável dos lotes

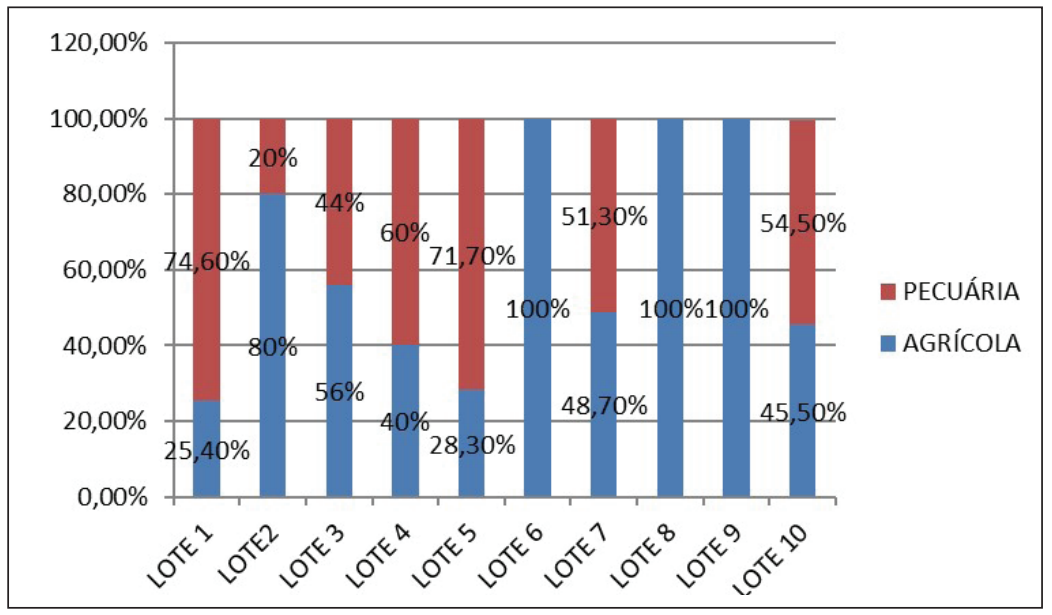

Fonte: Elaborado pelos autores.

Com exceção do posseiro do lote 9, todos estão inseridos em programas estatais para comercialização da sua produção agropecuária. Desses, nove estão inseridos nos projetos do PAA, três do PNAE e dois do PPAIS. Tais programas permitem a diversificação da produção nos lotes, com a comercialização da produção de hortas, pomares e roças de alimentos. 
Cada programa possui um limite de valor e o poder local demanda a entrega nas instituições beneficiadas. Além do consumo pelas famílias de parte do excedente da produção, outra parte é comercializada nos mercados locais. Assim, além da produção comercial, é possível melhorar a segurança alimentar da família.

O Quadro 4 apresenta a origem das rendas das famílias, dividindo a renda em agropecuárias - oriunda da comercialização da produção nos lotes e indicando a participação em alguma política pública de comercialização - e não-agropecuárias, originadas a partir de recebimento de salários em trabalhos efetuados fora dos lotes, aposentadorias e de programas assistenciais.

Quadro 4 - Divisão da origem da renda por lote

\begin{tabular}{|c|c|c|c|}
\hline Lote & $\begin{array}{c}\text { Produção A } \\
\text { gropecuária }\end{array}$ & $\begin{array}{c}\text { Produção } \\
\text { Não-Agropecuária }\end{array}$ & $\begin{array}{c}\text { Participação em Programas } \\
\text { de Comercialização }\end{array}$ \\
\hline 1 & $100 \%$ & $0 \%$ & (PAA, PNAE e PPAIS) \\
\hline 2 & $79,11 \%$ & 20,89 & (PAA) \\
\hline 3 & $84,30 \%$ & $15,70 \%$ & (PAA, PNAE) \\
\hline 4 & $69 \%$ & $31,00 \%$ & (PAA) \\
\hline 5 & $87,30 \%$ & $12,70 \%$ & (PAA, PNAE e PPAIS) \\
\hline 6 & $100 \%$ & $0 \%$ & (PAA) \\
\hline 7 & $93,60 \%$ & $6,40 \%$ & (PAA) \\
\hline 8 & $77 \%$ & $23 \%$ & \\
\hline 9 & $41 \%$ & $59 \%$ & (PAA) \\
\hline 10 & $100 \%$ & $0 \%$ & \\
\hline
\end{tabular}

Fonte: Elaborado pelos autores.

Mediante as informações apresentadas no Quadro 4, podemos afirmar que a maior fonte de renda dos lotes é a agropecuária. Já a renda não-agropecuária se origina principalmente das aposentadorias e de salário recebido fora dos lotes. Uma exceção é o lote 9, no qual a renda não-agropecuária representada pela aposentadoria do casal morador é a maior parte da renda da família. 
Essa família é a única que não acessou políticas públicas de crédito para financiamento dos meios de produção e incentivo à comercialização por não ter conseguido a DAP. A produção desse lote se concentra na agricultura com produtividade e diversidade produtiva baixas, refletindo na formação da renda familiar. Dentre as demais famílias, todas elas comercializam a produção no PAA.

Já o Quadro 5 mostra o peso (\%) de cada programa de política de comercialização na formação da renda agropecuária das famílias.

Quadro 5 - Porcentagem da renda agropecuária dos meios de comercialização

\begin{tabular}{|ccccc|}
\hline Lote & CEAGESP & $\begin{array}{c}\text { Mercado local e } \\
\text { Regional }\end{array}$ & $\begin{array}{c}\text { Agroindústria } \\
\text { (laticínio) }\end{array}$ & $\begin{array}{c}\text { Políticas Pú- } \\
\text { blicas }\end{array}$ \\
\hline 1 & $16,00 \%$ & $10 \%$ & $55,50 \%$ & $18,50 \%$ \\
\hline 2 & $69,00 \%$ & $0 \%$ & $20 \%$ & $11 \%$ \\
\hline 3 & $33,90 \%$ & $3,40 \%$ & $40,70 \%$ & $22 \%$ \\
\hline 4 & $24,40 \%$ & $62,10 \%$ & $0 \%$ & $13,50 \%$ \\
\hline 5 & $6,80 \%$ & $7,50 \%$ & $64,30 \%$ & $21,40 \%$ \\
\hline 6 & $93,30 \%$ & $0 \%$ & $0 \%$ & $6,70 \%$ \\
\hline 7 & $45,10 \%$ & $6,70 \%$ & $43,40 \%$ & $4,80 \%$ \\
\hline 8 & $86,60 \%$ & $0 \%$ & $0 \%$ & $13,40 \%$ \\
\hline 9 & $0 \%$ & $100 \%$ & $0 \%$ & $0 \%$ \\
\hline 10 & $36,30 \%$ & $2 \%$ & $54,50 \%$ & $7,20 \%$ \\
\hline
\end{tabular}

Fonte: Elaborado pelos autores.

Em média, as compras públicas representam 10\% da renda obtida. As famílias mantêm estratégias de comercialização empregadas antes de se tornarem beneficiárias das políticas institucionais, ou seja, constatou-se o aumento do número de canais de comercialização. Entretanto, após o início da venda para as compras públicas ocorreu uma diversificação na produção e na comercialização de sorte a cumprir os contratos firmados.

As rendas obtidas com os programas das políticas de comercialização são encaradas como uma forma de poupança pelas famílias, principalmente o PAA e a modalidade "Compra Direta", pois esta realiza o pagamento de acordo com a entrega dos produtos. 
No caso dos posseiros, a entrega e a parte fiscal são coordenadas pela ASPRAVI que posteriormente repassa aos produtores, conforme a produção entregue por cada família.

Também, a produção leiteira é vendida para a agroindústria através da ASPRAVI que possui no seu quadro associativo outros agricultores familiares que não os posseiros e os assentados. No ano de 2015, os posseiros conseguiram junto à prefeitura um tanque de resfriamento de leite que ficou em nome da ASPRAVI (Associação dos Produtores Rurais do Assentamento Vitória) e foi instalado no lote 5 do Figueira Branca, sendo o leite recolhido a cada dois dias pelo caminhão do laticínio. Tais contratos devem ser analisados como parte das estratégias de controle que se fazem presentes nesse território.

\section{Considerações Finais}

No caso do Figueira Branca, a conquista de um bairro e um espaço para moradia e trabalho de famílias pode ser interpretada como uma oportunidade de tomar posse de um território com potencialidade de desenvolvimento econômico e social. Posseiros sem a experiência anterior de se organizar e se constituir enquanto sujeitos de direitos, na sua convivência com os assentados, bem como com os demais atores do território, se apropriaram desta perspectiva, ao construir sua identidade enquanto posseiros. Esse processo de conquista de território e de direitos (cidadania) através do reconhecimento social pelo Estado foi discutido neste artigo, principalmente através do circuito de bloqueios e perspectivas que se faz presente no acesso à terra, ao PRONAF, à energia elétrica e às políticas de comercialização.

Portanto, dentro da disputa de interesses e diante da necessidade em conseguir construir uma rede de apoio que pudesse facilitar a superação de situações que beneficiassem a formação do grupo, foi necessário aos posseiros utilizar estratégias que os aproximassem de outros atores, de sorte a conduzi-los 
a processos sociais que lhes trouxessem benefícios na regularização fundiária, mas também para o reconhecimento de sua cidadania.

0 referido grupo teve origem junto a agricultores vinculados ao MST, no assentamento vizinho. Ele foi resultado do processo de territorialização e do fortalecimento da produção camponesa no entorno do assentamento União da Vitória, conquista que se expandiu por meio da luta dos posseiros. Houve um intercâmbio de experiências entre os assentados e posseiros como parte do preparo para a ocupação, criando laços que contribuíram para o desenvolvimento e o fortalecimento dos grupos.

Nesse sentido, a atuação do MST e da CPT foi preponderante na formação política desses indivíduos, principalmente por encararem as situações típicas que ocorreram ao longo de uma ocupação e luta pela terra, como foi o caso da resistência e desconfiança dos agricultores vizinhos que tinham receio de terem suas terras ocupadas.

Como resultado da sinergia entre esses atores, a luta pela posse da terra foi silenciosa, de bastidores, não ocorrendo uso da violência. Houve um reconhecimento e aceitação social da ação do grupo no território enquanto agricultores familiares, culminando na entrega pela prefeitura da declaração de posse pacífica para cada lote, atestando (simbolicamente) não existirem objeções relacionadas à posse da área.

0 acesso às políticas públicas de crédito e comercialização, que veio por intermédio da concessão da DAP e esta, por sua vez, conquistada após a declaração de posse mansa e pacífica, serviu para a construção de infraestrutura nos lotes. Entretanto, apesar de terem todos os pré-requisitos necessários à emissão da declaração, ainda foi necessário o envolvimento de uma rede de atores mais ampla para fazer valer as prerrogativas do pro- 
grama. Expressão dos bloqueios que permearam e fazem parte desse processo.

A obtenção da DAP simbolizou o reconhecimento institucional do grupo como agricultores familiares, por estarem de acordo com as exigências dos órgãos competentes em atribuir esta declaração e poderem se constituir como sujeitos de outras políticas públicas. Este reconhecimento social como agricultores não pode ser dado como único, nem como isento de tensões. No entanto, procurou-se mostrar como se dá a mediação entre as necessidades dos posseiros para serem sujeitos de políticas públicas e sua difícil consecução nos meandros da burocracia dos programas.

Como contrapartida, a DAP significou para os posseiros sentimentos de inclusão e pertencimento, o seu reconhecimento como agricultor familiar com o documento emitido por um órgão público. Este documento os habilitou a participar de programas que, anteriormente, lhes eram negados, vislumbrando, a partir do acesso às políticas públicas, melhoras na reprodução das famílias, caso da "poupança" advinda com o PAA e do aprimoramento da sua segurança alimentar.

Diante disso, a reflexão que se faz é sobre o reconhecimento social e institucional, que é conquistado em diferentes instâncias do poder, justamente pelos estamentos existentes. O esforço exigido pode ser diferente em cada nível de poder bastando, para tanto, o rearranjo nas estratégias do grupo juntamente com sua rede de atores, em uma trama de tensões, conquistas e bloqueios. Todo este processo possui reflexos em uma nova construção identitária de agricultor familiar, que aos poucos substituiu aquela preconceituosa sobre os moradores do lixão.

Objetivamente, os resultados apontam uma associação entre as políticas públicas e o panorama produtivo e de comercialização 
das famílias. A principal vantagem está na diversificação produtiva para atender às demandas das entidades conveniadas nos programas de comercialização e no investimento em estufas para cultivo de olerícolas presentes em oito dos dez lotes pesquisados. Com exceção do posseiro do lote 8, que adquiriu as estufas com recursos próprios, os posseiros dos demais lotes restantes financiaram suas estufas pelo PRONAF Mais Alimentos.

Cabe recordar que existe na região toda uma logística que impulsiona a produção de olerícolas em estufas, com o apoio da CATI, outras que foram subsidiadas pelo INCRA e pelo ITESP, destacando a produção de pepino, pimentão e tomate. Essa é, de fato, uma cadeia produtiva liderada pela competência técnica da produção de legumes em estufa, com ambiente tecnificado e intenso em uso de insumos extra setoriais, agrotóxicos e capital. Por outro lado, a comercialização depende dos atravessadores e de canais convencionais, como o circuito até os boxes da Companhia de Entrepostos e Armazéns Gerais de São Paulo - Ceagesp. Ao mesmo tempo, atende a um mercado de produtos padronizados e de consumo em massa nos grandes centros urbanos. 0 acesso ao PRONAF, neste caso, permitiu a diversificação da produção dos lotes, acrescentando um novo sistema produtivo dentro da lógica de produção agropecuária convencional. A produção de leite, por sua vez, tem sido uma atividade com possibilidades de financiamento e que possui ligação mais forte com os modos de vida dos posseiros e seus hábitos de produção, consumo e comercialização (mesmo que para laticínios).

Trata-se, pois, de um caso concreto que vem demonstrar que a cidadania envolve luta por direitos, não podendo ser discutida somente a partir de tutelas e concessões. Este estudo de caso permitiu estabelecer alguns contrapontos à teoria e mostrou a tensão entre a resistência da burocracia executora das políticas públicas em incorporar direitos sacramentados nos textos de normas e leis. Muitas vezes, o reconhecimento ocorre pela capacidade dos sujeitos em resistir e de construir uma trama de 
relações que supere os bloqueios e contribua para a ação solidária na conquista da cidadania e de maior equidade social e econômica. No entanto, mesmo após conquistas como a terra e a cidadania, a trajetória e o desenvolvimento das famílias posseiras em atividades produtivas dependem de inúmeras relações entre as famílias e os agentes do território, que passam pelas políticas públicas, mas não podem ser condicionadas apenas a elas.

\section{Ref erências}

Aquino, J. R. Avanços e limites da política de crédito do PRONAF no Brasil (1996-2008): uma reflexão crítica. In: XLVII Congresso da Sociedade Brasileira de Economia, Administração e Sociologia Rural, 2009, Porto Alegre-RS. Anais... Brasília-DF: XLVII SOBER. v.1. pp. 1-21.

Bergamasco, S.; Norder, L. A. C. 0 que são assentamentos rurais? São Paulo: Brasiliense, 2001.

Carneiro, M. J. Política pública e agricultura familiar: uma leitura do PRONAF. Estudos Sociedade e Agricultura, Rio de Janeiro, Abril, vol.8, pp. 7082, 1997.

Chagas, M. F. Colonos e/ou posseiros: o uso das diferenças na construção das identidades. Oficina do Historiador, pp. 873-891, 2014.

Esquerdo, V. F. S.; Bergamasco, S. M. P. P. Análise sobre o acesso aos Programas de Políticas Públicas da Agricultura Familiar nos municípios do Circuito das Frutas (SP). RERS, Piracicaba-SP, Vol. 52, Supl. 1, pp. S205-222, 2014.

Feliciano, C. A. A prática da violência no campo brasileiro do século XXI. Coleção Território e Questão Agrária. São Paulo: Expressão Popular, 2015.

Furtado, C. BRASIL a construção interrompida. Rio de Janeiro: Paz e Terra, ed. 3, 1992.

Godoi, E. P.; Menezes, M.; Marin, R. A. (Orgs.). Diversidade do Campesinato: expressões e categorias. Coleção História Social do Campesinato no Brasil. São Paulo: UNESP, 2009. 385p.

Graziano Da Silva, J. 0 que é questão agrária. São Paulo: Ed. Brasiliense, 1980.

Grisa, C.; Schneider, S. Três gerações de políticas públicas para a agricultura 
familiar e formas de interação entre sociedade e Estado no Brasil. In: Políticas públicas de Desenvolvimento Rural no Brasil. Porto Alegre: UFRGS, 2015, pp.19-51.

Henig, E. V.; Santos, I. Â. Políticas públicas, agricultura familiar e cidadania no Brasil: o caso do PRONAF. Rev. Bras. Polít. Públicas, Brasília, v.6, n¹, pp. 255270, 2016.

Honneth, A. Luta por reconhecimento: a gramática moral dos conflitos sociais. São Paulo: ed. 34, 2003.

Instituto De Colonização E Reforma Agrária - INCRA. Diretoria de Ordenamento Fundiário/SNCR. Disponível em: <www.incra.gov.br>. Acesso em: dez. 2017.

Jorge, W. J.; Souza, J. G. Os Programas Especiais de Financiamento como Instrumentos de Integração Sócio-Econômica em Assentamentos Rurais: As intenções e os Fatos. In: Bergamasco, S.; Aubreé, M.; Ferrante, V. L. S. B. Dinâmicas Familiar, Produtiva e Cultural nos Assentamentos Rurais de São Paulo. Campinas: BAE UNICAMP, 2003, pp. 187-212.

Lamarche, H. (Coord.). A agricultura familiar. Comparação internacional. Campinas: Ed. Unicamp, 1993.

Martins, J. S. A militarização da questão agrária no Brasil. Petropólis: Ed. Vozes, 1984.

. O poder do atraso. São Paulo: Hucitec, 1999.

. 0 sujeito da reforma agrária. In: Martins, J. (Org.). Travessias: a vivência da reforma agrária nos assentamentos. Porto Alegre: UFRGS, 2003. pp. 11-52.

Neves, D. P. Associativismo e personalismo dos mediadores formais: dilemas da organização política de assentados rurais pela intervenção estatal. Retratos de Assentamentos, Araraquara, v.16, pp.15-42, 2013.

Picolotto, E. L. Os atores da Construção da Categoria Agricultura Familiar no Brasil. RSER, Piracicaba-SP, Vol. 52, Supl. 1, pp. S063-S084, 2015.

Prado Júnior, C. A Questão Agrária. São Paulo: Ed. Brasiliense, 5 edição, 2000. SANTOS, M. 0 espaço do cidadão. São Paulo: Ed. Edusp, $7^{\circ}$ ed, $2^{\circ}$ reimpressão. 2014. Silva, R. P.; Aly Júnior, O.; Luchini, J. D.; Ferrante, V. L. S. B. PRONAF e a produção familiar: a diversidade do tecido social na órbita do Estado. Retratos de Assentamento, Araraquara-SP, v.18, n.2, pp. 341-366, 2015.

Sousa Santos, B. Pela mão de Alice: o social e o político na pós-modernidade. São Paulo: Cortez, 1995.

Souza, J. Uma teoria crítica do reconhecimento. LUA NOVA N $50,2000$. 
Ventura, T. Luta social por reconhecimento: dilemas e impasses na articulação pública do desrespeito. Rev. Sociol. Polit., v. 19, n. 40, pp. 159-170, 2011.

Wagner, D.; Gehlen, I.; Schultz, G. Agricultura Familiar, Políticas Públicas e Cidadania: Conexões construídas a partir da operacionalização do Programa Nacional de Alimentação Escolar. REDES, v.21, n³ 3, pp.121-145, set/dez. 2016.

Wanderley, M. N. B. Raízes Históricas do Campesinato Brasileiro. XX Encontro Anual da ANPOCS. GT 17. Processos Sociais Agrários. Caxambu-MG. Outubro 1996. In: Anais..., 1996.

Agricultura familiar e campesinato: rupturas e continuidade. Estudos Sociedade e Agricultura, Rio de Janeiro, 21, Outubro, pp. 42-61, 2003. 